\title{
Evaluation of variable speed pumps in pressurized water distribution systems
}

\author{
Farzin Salmasi $^{1}$ [D John Abraham ${ }^{2} \cdot$ Arian Salmasi $^{3}$
}

Received: 7 September 2021 / Accepted: 21 January 2022 / Published online: 18 February 2022

(c) The Author(s) 2022

\begin{abstract}
In pressurized water distribution systems, a constant speed pump is often used because of its simplicity. However, constant speed pumps are not easily able to deal with changing demands in water flows. When the demand for the discharge differs from the design discharge, the required demand (discharge and head) could be met by changing the pump speed without making any special changes in the system. Using an electronic drive circuit, the electrical frequency can be changed, and the rotation speed of the pump motor can thus be modified. In this study, the application of variable speed pumps in pressurized irrigation systems is investigated. Two pumping station scenarios including a fixed speed pump and a variable speed pump are considered. The selected pump station includes a real sprinkler irrigation system near Tabriz city, Iran, with 3 lateral pipes and $600 \mathrm{~m}$ length of main pipe. The diameter of the main pipes is 8 and 6 inches. The results show that using a variable speed pump increases the average pump efficiency by $18.7 \%$. In addition, the variable speed pump system reduces the electrical consumption $57.6 \%$ compared to a fixed speed pump. Therefore, the use of variable speed pumps in pressurized systems is recommended. Step-by-step calculations for a sprinkler irrigation system design are the contribution of this study. This information helps engineers who are not familiar with commutation process.
\end{abstract}

Keywords Pumping station $\cdot$ Variable speed pump $\cdot$ Pressurized pipe $\cdot$ Efficiency $\cdot$ Pump power

\section{Introduction}

In recent years, the cost of energy has increased faster than other agricultural costs. While agricultural pumping stations, their energy consumption and efficiencies have been improved (Abadia et al. 2008), there are still opportunities for further improvements. Water pumping stations usually use fixed speed pumps that have a good efficiency over a small range of pressure and flows. If different flows and pressures are required,

Farzin Salmasi

Salmasi@tabrizu.ac.ir

John Abraham

jpabraham@stthomas.edu

Arian Salmasi

ariansalmasi9@gmail.com

1 Department of Water Engineering, Faculty of Agriculture, University of Tabriz, Tabriz, Iran

2 School of Engineering, University of St Thomas, 2115 Summit Avenue, Saint Paul, MN 55105, USA

3 Faculty of Chemistry, University of Tabriz, Tabriz, Iran unsuitable pump speeds will yield excessive energy losses. This imposes additional costs, especially on pressurized irrigation systems, which are constantly changing their irrigation needs, sometimes monthly.

Today, more than $60 \%$ of electricity consumption in the industry is from electric motors. Therefore, increasing their efficiency leads to significant savings in energy consumption ( $\mathrm{Li}$ et al. 2019) and a reduction in pollution and emission of greenhouse gases that cause climate change ( $\mathrm{Li}$ et al 2020; Cheng et al. 2020; Cheng et al. 2019). Constant speed pumps have a fixed rotational speed of the impellers which limit the ability to modify the flow. Consequently, use of a constant speed of impeller reduces the flexibility of the pumping system. In contrast, there are variable speed pumps (VSP) that have the ability to adjust the impeller rotation and can be used to make desired changes in the pumping system.

In the information provided by the pump manufacturers, discharge-head curves are usually provided for several impeller diameters and for two or more limited impeller speeds. With VSP, the pump is theoretically capable of operating on an unlimited number of pump curves that range between a minimum and a maximum. When the discharge demand differs 
from the design, the required demand (discharge and head) can be met by making a change in the pump without making any special changes in the system and without imposing additional costs (Lamaddalene and Khila 2012). In this regard, the following considerations may be important:

(i) As the head loss increases in the pressurized pipe system, the required head increases.

(ii) Over time and with the development of the irrigation and drainage project area, the need for discharge and head will increase.

(iii) In the months when the water requirement of the irrigation plan is less than the maximum, the need for discharge and head is reduced. With proper use of VSP in the pumping station, the required discharge and head can be adjusted every month, or with other frequencies.

Due to the dependence of pressurized irrigation systems on the pumping stations, various methods for improving energy consumption have been studied. Fernandez-Pacheco et al. (2015) investigated variable speed drives used in centrifugal pumps. They found that conventional discharge control methods use a control valve that reduces the efficiency of the pump and increases the operating head of the pump. By examining the characteristic curves of the pump and the system, they showed that the use of speed adjustment drives to reduce the flow rate increases the efficiency and reduces the losses significantly.

Hanson et al. (1996) divided an irrigation area into five sections and considered different irrigation conditions in each section. They used a variable frequency drive to change the rotational speed in the pump and to provide the required discharge in individual sections. They found that the energy consumption of the studied sections when using a variable frequency drive led to an energy reduction of 32-56\%.

Lamaddalene and Sagardoy (2000) studied pressurized irrigation systems. They proposed a way to increase pump efficiency, which would reduce the conflict between farmers and the problems caused by improper use of irrigation water. Due to the change in the curve of variable speed pumps at different speeds, Lamaddalene and Sagardoy (2000) were able to calculate energy consumption according to changes in system needs. They found that power consumption was reduced by $5-21 \%$ if a variable speed pump was used.

Moreno (2008) proposed a new method for determining the characteristic curve of pumps and the efficiency of the pumping stations that can be used to calculate the necessary parameters for the selection of the pump. Using this method, pump selection can occur more accurately and energy can be saved.

Diaz et al. (2009) investigated energy storage in irrigation networks that are adjusted based on the required head. They selected an area in southern Spain and surveyed that area under four management scenarios with different levels of water demand. The results showed that the use of methods such as
VSP and zoning significantly reduced the water demand of pumping stations by more than $27 \%$. Lamaddalene and Khila (2012) investigated energy savings by using a variable speed pump in two irrigation areas in southern Italy. They used COPAM software to determine the pipe system characteristic curve and showed that the energy consumption is reduced by $27-35 \%$.

These results are consistent with the results of studies such as Lamaddalene and Sagardoy (2000); and Diaz et al. (2011). However, depending on the conditions of each design, whether agricultural or industrial, the amount of savings in water and energy consumption and increase in efficiency will be different.

Khayatzadeh and Ghafouri (2015) developed a centrifugal pump system that incorporated multiple stages, each coupled to an induction motor. Two different flow control strategies were used that involved both constant and variable speed pumping methods. The authors found a very large (83\%) energy savings when the variable pumping system was employed.

Khadra et al. (2016) used a multi-step approach to incorporate pressure and pumping requirements for pumping stations with fixed and variable head control. They focused on an on-demand irrigation system in Italy and found that under an optimal scenarios, a $49 \%$ improvement in performance could be achieved.

\section{Application of a variable frequency drive (VFD)}

Variable frequency drive (VFD) refers to a type of motor controller that can rotate the electric motor by changing the frequency and voltage in the electric motor. Other names used for electric drives include: variable speed driver, adjustable speed drive, adjustable frequency drive, $\mathrm{AC}$ drive, micro drive and inverter.

Frequency (or $\mathrm{Hz}$ ) is directly related to motor speed (rpm). In other words, the higher the frequency, the faster the motor speed. If the user does not need an electric motor that rotates at full speed, an electric drive can be used to lower the frequency and voltage to meet the requirements of the electric motor. As the required motor speed in the intended application changes, the electric drive can easily meet modified requirements by raising and lowering the motor speed. A VFD circuit consists of three parts: (i) the rectifier section, (ii) the filter section and (iii) the switching or inverter section.

Most variable frequency drives first convert the input power to direct current (DC) and then return it to alternating current (AC) at the desired frequency. The particular method the drive uses to convert direct current to alternating current depends largely on the size and power of the motor. With less expensive systems, the output voltage is usually square, which is not a problem for AC motors, but sometimes an extra unit is used to bring the waveform closer to a sine waveform (Zell 1989). 


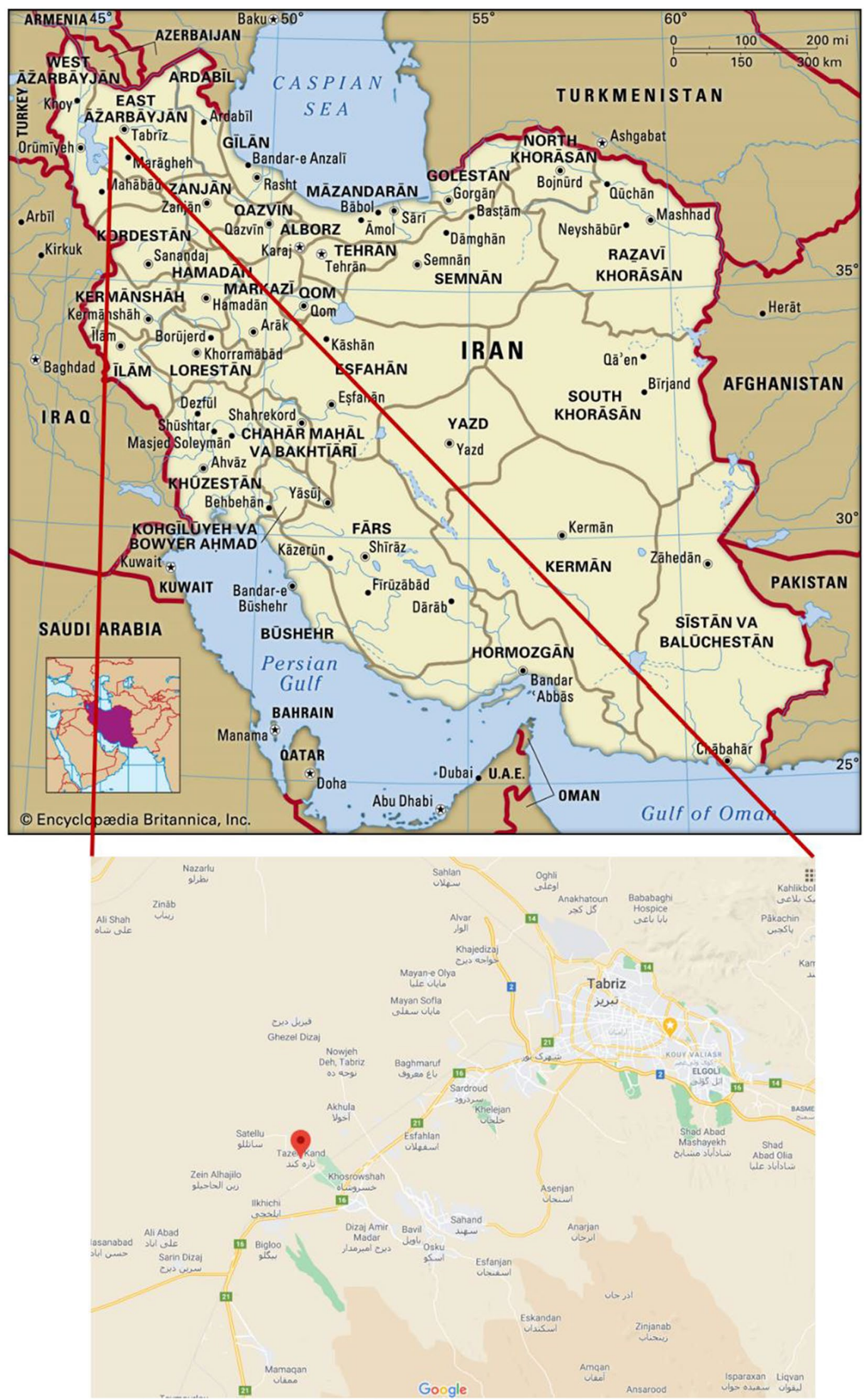

Fig. 1 Location of the test site in the Tazeh Kand village near Tabriz, Iran 
The converter consists of six diodes, which are similar to the one-way valves used in piping systems. These diodes provide current in only one direction. For example, if the voltage of phase $\mathrm{A}$ is more positive than the voltages of phase $\mathrm{B}$ or $\mathrm{C}$, then the desired diode opens and current flows. If phase $B$ is more positive than phase $\mathrm{A}$, then the phase $\mathrm{B}$ diode opens and the phase A diode closes. The same situation occurs for the 3 diodes on the negative side. Therefore, six pulses of current are generated when each diode is opened and closed. This is called a six-pulse electric drive, which is the standard configuration for variable frequency drive drives.

However, despite the VFD advantages, there are a few disadvantages also associated with the VFD system. The primary drawback of the VFD system is the initial setup investment. For a factory or a plant where multiple high horsepower motors need to be controlled using VFDs, requires high investments. In addition, VFD causes motor heating and needs special motors construction. The construction needs special types of Motor insulations, as well as the motors need to be specified for inverter rated applications (Ruminski 2016). More details

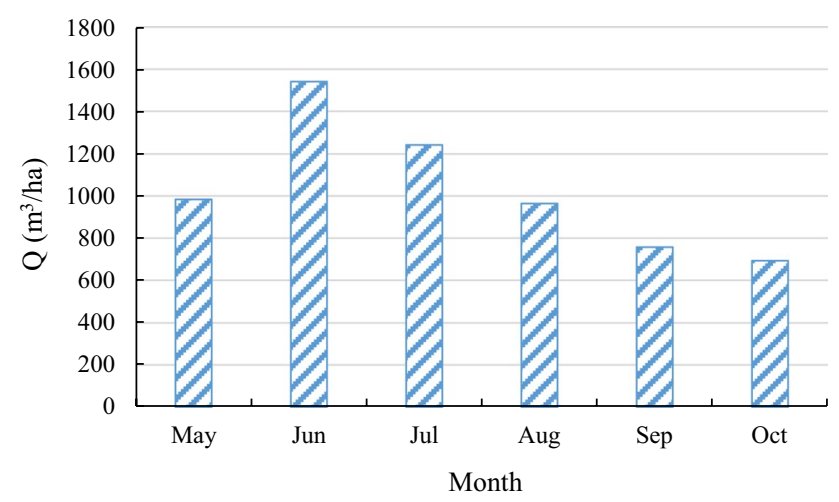

Fig. 2 Average monthly irrigation water demand about VFD are beyond of this paper and more information can be found in Lee et al. (2020) and Ramesh et al. (2020).

The present study is carried out to evaluate the efficiency of variable speed pumps in water distribution systems. Two types of pumping stations (constant speed and variable speed) are considered. The area of agricultural lands is 70 hectares with wheat, corn and alfalfa crops around the city of Tabriz, Iran. The purpose of the study is to reduce the electricity consumption.

\section{Material and methods}

\section{Site location and sprinkler irrigation characteristics}

One of the design goals of each pumping station is that the pump operates close to its optimal efficiency. However, during operation, the pumping system may experience many fluctuations. As a result, setting a constant speed for a pump that operates near its optimum condition is difficult. This enhances the need to change the design of pumping stations.

The agricultural study is located in Tazeh Kand village, $30 \mathrm{~km}$ southwest of Tabriz. The water pumping station includes a fixed speed centrifugal electric motor pump for use in a sprinkler irrigation system. The selection of this pump is based on the maximum consumption of the sprinkler irrigation network in July. Figure 1 shows the location of the farm under study.

Figure 2 provides average monthly irrigation water demand during cultivation time from May-October. The maximum irrigation network consumption in July is $1541.05 \mathrm{~m}^{3} / \mathrm{ha}$. October has the minimum irrigation demand of $692.81 \mathrm{~m}^{3} /$ ha.

As shown in Fig. 3, in the sprinkler irrigation system, three lateral pipes are connected to the main pipe. The required discharge for these three lateral pipes is $0.020 \mathrm{~m}^{3} / \mathrm{s}$. The required head at the inlet of each lateral pipe is $35.14 \mathrm{~m}$. The pipes are made of polyvinyl chloride (PVC) and the system capacity is

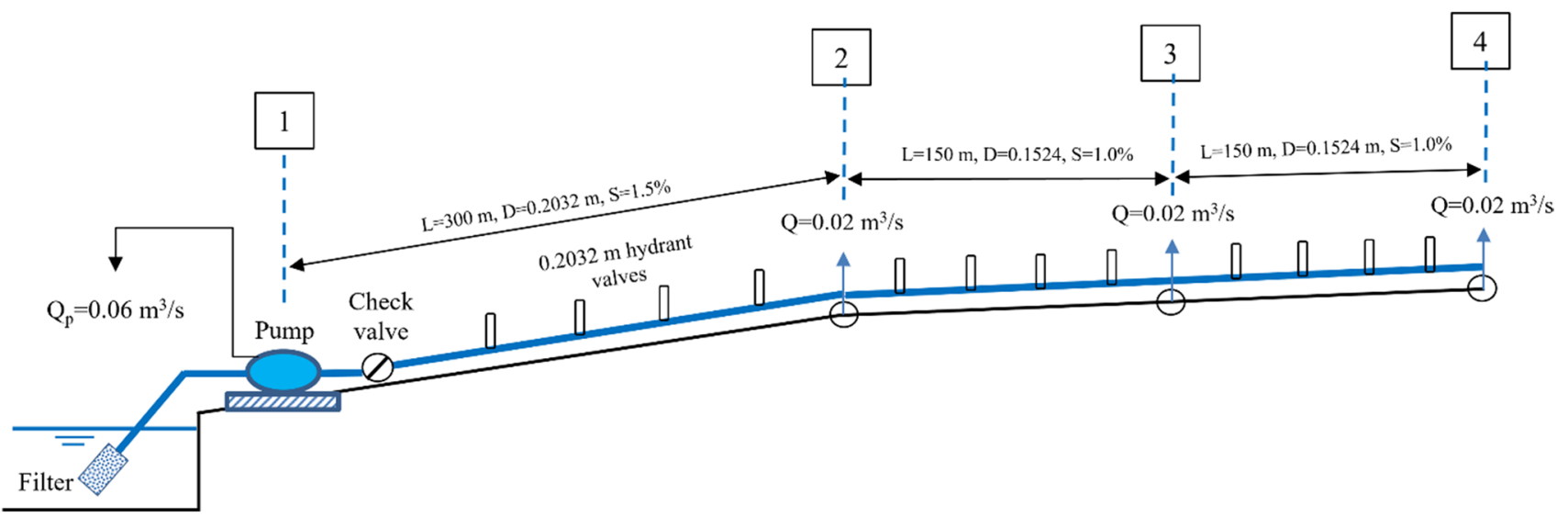

Fig. 3 Sprinkler irrigation system consists of three lateral pipes branching from the main pipe 
Table 1 Friction loss $\left(h_{f}\right)$ in the main pipe between stations 1 and 4

\begin{tabular}{llllllll}
\hline Pipe part & $Q\left(\mathrm{~m}^{3} / \mathrm{s}\right)$ & $D(\mathrm{~m})$ & $L(\mathrm{~m})$ & $C$ & $h_{f}(\mathrm{~m})$ & $V(\mathrm{~m} / \mathrm{s})$ & $V^{2} / 2 g$ \\
\hline Part 1-2 & 0.06 & 0.2032 & 300 & 150 & 3.86 & 1.851 & 0.175 \\
Part 2-3 & 0.04 & 0.1524 & 150 & 150 & 3.70 & 2.194 & 0.245 \\
Part 3-4 & 0.02 & 0.1524 & 150 & 150 & 1.02 & 1.097 & 0.061 \\
Sum & & & & & $\mathbf{8 . 5 9}$ & & \\
\hline
\end{tabular}

Table 2 Head loss in valves, fixtures and bends between stations 1 and 4

\begin{tabular}{llll}
\hline Part 1-2 & No & $K$ & $h_{f}(\mathrm{~m})$ \\
\hline Check valve 0.2032 m & 1 & 1.3 & 0.227 \\
Elbow 45 Deg & 2 & 0.6 & 0.210 \\
Hydrant 0.2032 m & 4 & 0.3 & 0.210 \\
3 way 0.2032 m & 1 & 0.5 & 0.087 \\
\hline Part 2-3 & No & $\mathrm{K}$ & $\mathrm{h}_{\mathrm{f}}(\mathrm{m})$ \\
\hline Hydrant 0.1524 m & 4 & 0.3 & 0.294 \\
3 way 0.1524 m & 1 & 0.5 & 0.123 \\
\hline Part 3-4 & No & $\mathrm{K}$ & $\mathrm{h}_{\mathrm{f}}(\mathrm{m})$ \\
\hline Hydrant $0.1524 \mathrm{~m}$ & 4 & 0.3 & 0.074 \\
\hline
\end{tabular}

Table 3 Total dynamic head required by the sprinkler irrigation system

\begin{tabular}{ll}
\hline Description & Head (m) \\
\hline Required head at the beginning of lateral pipe & 35.14 \\
Friction head loss at main pipe line (Table 1) & 8.59 \\
Head loss from valves, bends, etc. (Table 2) & 1.22 \\
Sum of suction head and difference in elevation between & 10 \\
$\quad$ stations 1 and 4 (2.5 + 7.5) & 1 \\
Head loss due to filter in the suction pipe & 2.16 \\
Extra head losses (20\% of friction head loss) & 58.11 \\
Total dynamic head &
\end{tabular}

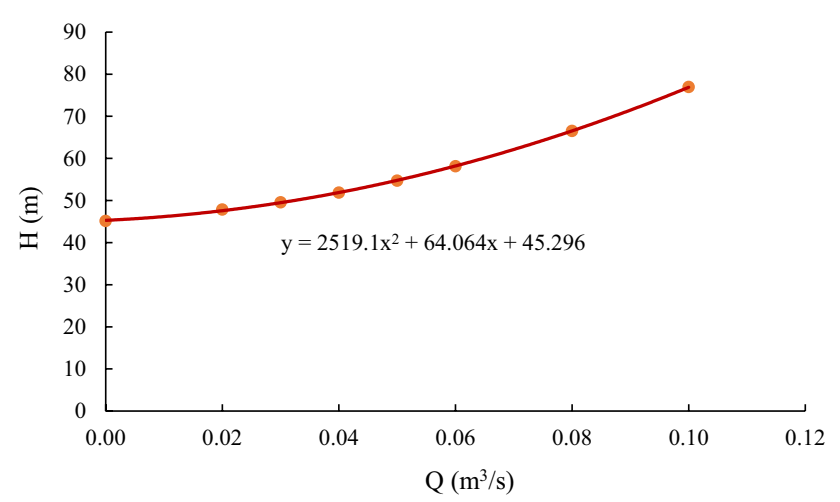

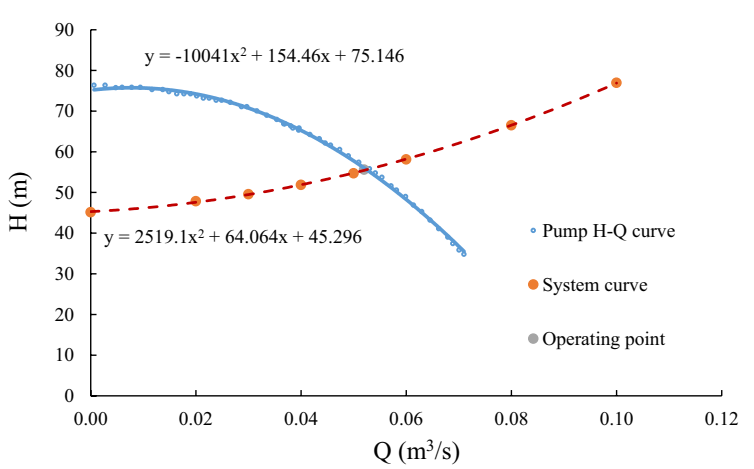

(a) The intersection of the pump characteristic curve and the system curve determine the operating point

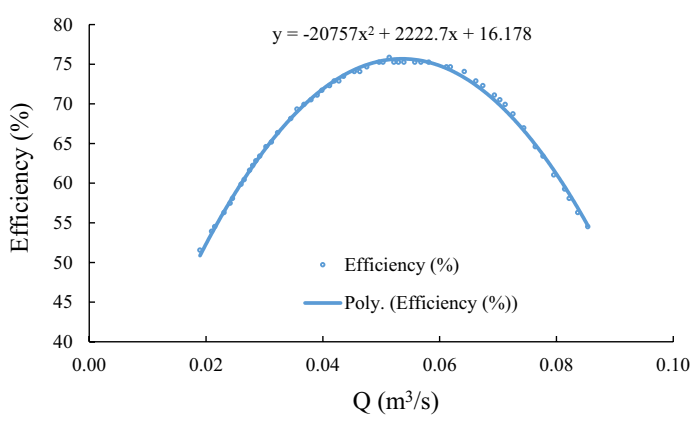

(b) Variation of pump efficiency against discharge

Fig. 5 Pump and system characteristic curves

$0.06 \mathrm{~m}^{3} / \mathrm{s}$. The suction head is $2.5 \mathrm{~m}$ and the friction loss due to the joints, bends and filter in the suction pipe is equal to $1.0 \mathrm{~m}$.

\section{Head loss calculations}

The useful power of the pump $(P)$ is the amount of energy that is transferred to the fluid per unit time by the pump and is calculated as follows:

$P=\gamma Q H_{T}$

In Eq. (1), the specific gravity of the fluid $(\gamma)$ is in terms of $\mathrm{N} / \mathrm{m}^{3}$, the discharge $(Q)$ is in $\mathrm{m}^{3} / \mathrm{s}$, and the total dynamic head $\left(H_{T}\right)$ of the pump has units of $\mathrm{m}$. With these units, the useful power will be in terms of watts (W). The $H_{T}$ is defined as sum of the geometric head and the friction head. Geometric head is the difference between water levels in suction and delivery

Fig. 4 System curve for sprinkler irrigation network 
Table 4 Calculation of efficiency, brake power and electrical consumption of sprinkler irrigation system in the current design conditions (constant speed pump)

\begin{tabular}{|c|c|c|c|c|c|c|c|}
\hline Parameter & May & June & July & August & September & October & Sum \\
\hline Water requirements $\left(\mathrm{m}^{3} / \mathrm{ha}\right)$ & 984.13 & 1541.05 & 1242.44 & 964.54 & 757.35 & 692.81 & \\
\hline Total water requirements ( $\mathrm{m}^{3}$ for $70 \mathrm{ha}$ ) & $68,889.1$ & $107,873.5$ & $86,970.8$ & $67,517.8$ & $53,014.5$ & $48,496.7$ & \\
\hline Pump discharge, $\mathrm{Q}\left(\mathrm{m}^{3} / \mathrm{s}\right)$ & 0.0398 & 0.0460 & 0.0431 & 0.0364 & 0.0332 & 0.0331 & \\
\hline Pump operating time (hr) & 15.500 & 21.700 & 18.100 & 16.600 & 14.800 & 13.110 & 99.810 \\
\hline $\mathrm{TDH}(\mathrm{m})$ & 65.372 & 60.982 & 63.182 & 67.438 & 69.223 & 69.234 & \\
\hline Net power, $\mathrm{P}(\mathrm{kw})$ & 25.540 & 27.536 & 26.687 & 24.111 & 22.523 & 22.513 & \\
\hline Pump Efficiency without varied speed (\%) & 71.78 & 74.51 & 73.40 & 69.61 & 67.06 & 67.05 & \\
\hline Brake power $(\mathrm{kw})$ & 35.58 & 36.96 & 36.36 & 34.64 & 33.58 & 33.58 & \\
\hline Electrical consume (kwh) & 551.53 & 801.96 & 658.09 & 574.95 & 497.05 & 440.20 & 3523.774 \\
\hline
\end{tabular}

reservoirs. Friction head includes sum of the friction head and minor head losses due to bends, valves, transitions, etc.

Pump efficiency $(\eta)$ is the ratio of the useful power of the pump to the power required to operate the pump (known as brake power, BP).

$\eta=\frac{P}{B P}$

The efficiency of centrifugal pumps is usually between 60 and $90 \%$.

The application of the law of similarity for pumps adapts the pump to the water supply system. This means that the discharge or head can be changed by changing the rotation speed of the pump impeller; the pump flow is directly related to the impeller rotation speed. Using this concept, the following expression can be written.

$\frac{Q_{1}}{Q_{2}}=\frac{r p m_{1}}{r p m_{2}}$

where $Q$ is the pump discharge and rpm is the rotation speed of the pump impeller.

On the other hand, the head or the total dynamic head produced by the pump is proportional to the square of the discharge according to the Darcy-Weisbach relation. Therefore, we have:

$\frac{H_{1}}{H_{2}}=\left(\frac{r p m_{1}}{r p m_{2}}\right)^{2}$

Brake power is proportional to the third power of the discharge according to Eq. (5).

$\frac{B P_{1}}{B P_{2}}=\left(\frac{r p m_{1}}{r p m_{2}}\right)^{3}=\left(\frac{Q_{1}}{Q_{2}}\right)^{3}$

The total dynamic head for a system is calculated using the following procedure that will now be described in detail.

In Fig. 2, the lateral pipe is critical at station 4 (because it is both at a greater distance and at a higher altitude than the rest of the locations). The required head or pressure at the beginning of the lateral pipe is equal to $35.14 \mathrm{~m}$. Using the slope of the natural ground $(S)$ and the length of the pipe $(L)$, the elevation difference between the stations 1 and 4 is:

$H=\sum_{i=1}^{3} L_{i} S_{i}=300 \times 0.015+2 \times 150 \times 0.01=7.5 m$

The calculation of the friction loss $\left(h_{f}\right)$ in the main pipe between stations 1 to 4 using the Hazen-Williams relation is presented in Table 1 where $C$ is the coefficient of friction in the Hazen-Williams relation and is assumed to equal 150 for PVC pipe. In addition, $V$ denotes to the mean flow velocity in pipe (Table 1).

Head loss occurs because intermediate structures such as valves, bends and pipe transitions result in a pressure decrease in the flow. These loss terms are often distinguished from frictional losses and are sometimes termed "minor losses." The minor loss term $\left(h_{f}\right)$ is calculated according to Fig. 2 and Table 2; in the table, $K$ refers to the loss coefficient in valves and fittings. The last column in Table 2 is obtained from the following equation.

$h_{f}=K \times \frac{V^{2}}{2 g}$

The summation of all the above-noted head loss terms is $1.22 \mathrm{~m}$. With this value now determined, it is possible to calculate the total head required to generate the necessary flow. That calculation is shown in Table 3.

The maximum network consumption in July is $0.06 \mathrm{~m}^{3} / \mathrm{s}$ and the total dynamic head is $58.11 \mathrm{~m}$. To determine the system curve for the variable discharge, the total dynamic head value must be calculated according to the above method (Tables 1, 2 and 3) for a number of discharge flows. Typically, a few discharge flows are selected above and below the designed value $\left(0.06 \mathrm{~m}^{3} / \mathrm{s}\right)$ in this case. The resulting system curve from these calculations is provided in Fig. 4. 


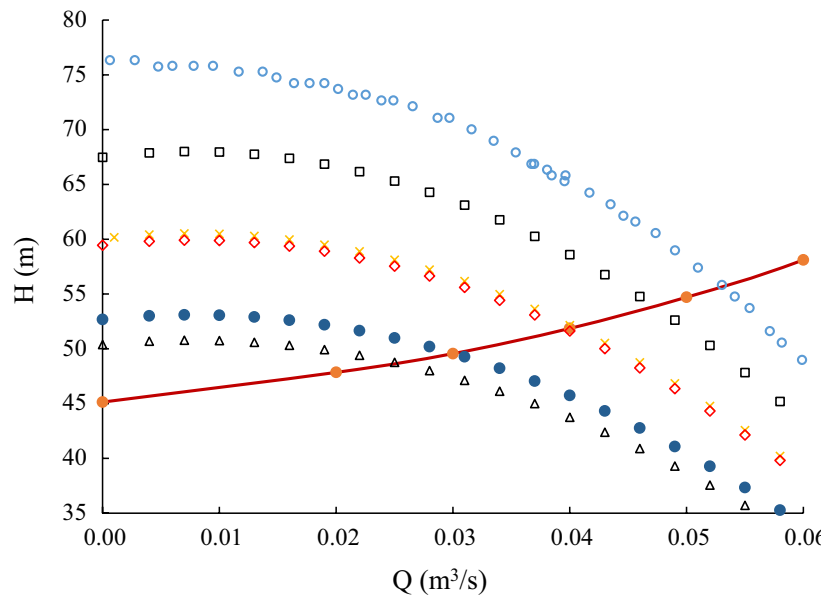

\begin{tabular}{|ll|}
\hline- System curve & $\circ$ Pump curve, N=1450 rpm \\
$\triangle \quad$ Pump curve, N=1169.03 rpm & $\times$ Pump curve, N=925.98 rpm \\
$\diamond$ Pump curve, N=907.55 rpm & - Pump curve, N=712.60 rpm \\
$\triangle$ Pump curve, N=651.88 rpm & \\
\hline
\end{tabular}

Fig. 6 Operating points of the system at different pump speeds

It should be noted that the intersection of the system curve (Fig. 4) with the $y$-axis is $45.14 \mathrm{~m}$, which is the sum of the required head at the beginning of the lateral pipe, the sum of the suction head and the height difference between stations 1 and 4 .

Based on these calculations, a suitable centrifugal pump type EA-125-50/2 has been selected. At a $50 \mathrm{~Hz}$ frequency, the engine speed is $1450 \mathrm{rpm}$. The diameter of the pump impeller is $0.319 \mathrm{~m}$.

In Fig. 5a, the characteristic curves of the pump and the characteristic curve of the pipe system are plotted together and their intersection defines the operating point. Based on Fig. 5a, the operating point of the pump is found to correspond to $Q=0.052$ $\mathrm{m}^{3} / \mathrm{s}$ and $H=55.60 \mathrm{~m}$.

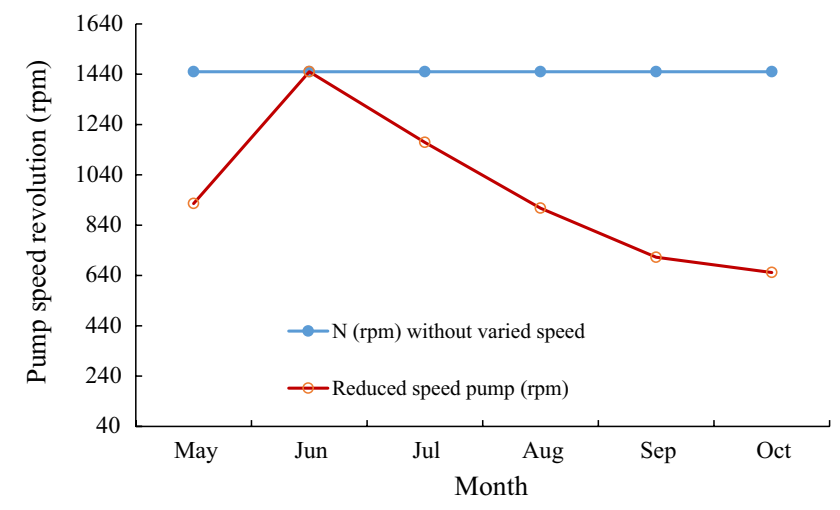

Fig. 7 Variation of pump impeller rotation in different months for fixed speed pump and variable speed pumps

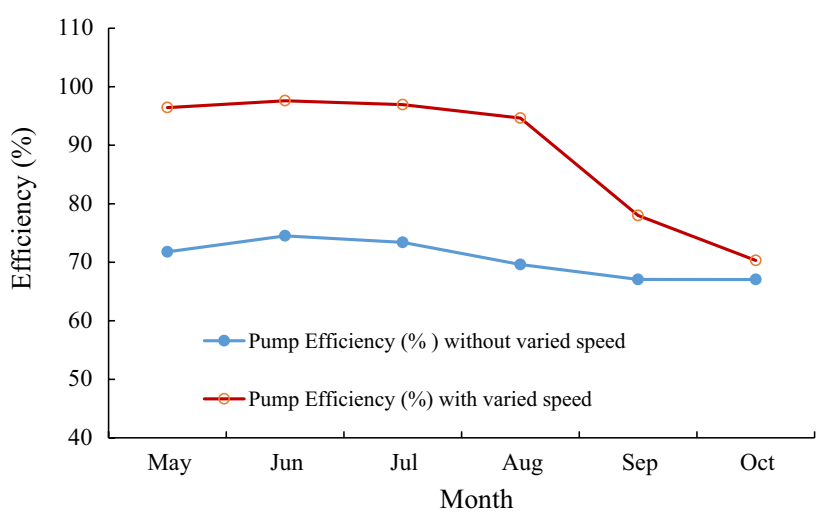

Fig. 8 Variation of pump efficiency in different months for two modes of fixed speed pump and variable speed pump

According to the pump manufacturer, the pump efficiency versus discharge is shown in Fig. 5b. At a design flow rate of $0.06 \mathrm{~m}^{3} / \mathrm{s}$, the pump efficiency is $74.81 \%$.

Table 4 presents the calculation of efficiency, brake power and electricity consumption of the sprinkler irrigation system

Table 5 Calculations of efficiency, brake power and electricity consumption of the sprinkler irrigation system using a variable speed pump (VSP)

\begin{tabular}{|c|c|c|c|c|c|c|c|}
\hline Parameter & May & June & July & August & September & October & Sum \\
\hline Water requirements $\left(\mathrm{m}^{3} / \mathrm{ha}\right)$ & 984.13 & 1541.05 & 1242.44 & 964.54 & 757.35 & 692.81 & \\
\hline Total water requirements $\left(\mathrm{m}^{3}\right.$ in $\left.70 \mathrm{ha}\right)$ & $68,889.1$ & $107,873.5$ & $86,970.8$ & $67,517.8$ & $53,014.5$ & $48,496.7$ & \\
\hline Reduced speed pump (rpm) & 925.98 & 1450.00 & 1169.03 & 907.55 & 712.60 & 651.88 & \\
\hline Pump operation (hr) & 15.432 & 19.208 & 16.581 & 15.513 & 16.363 & 16.714 & 99.810 \\
\hline $\mathrm{Q}$ in operating point $\left(\mathrm{m}^{3} / \mathrm{s}\right)$ & 0.04 & 0.052 & 0.047 & 0.039 & 0.03 & 0.026 & \\
\hline $\mathrm{H}$ in operating point $(\mathrm{m})$ & 51.980 & 55.600 & 53.930 & 51.800 & 49.530 & 48.600 & \\
\hline Net power, $\mathrm{P}(\mathrm{kw})$ & 20.40 & 28.36 & 24.87 & 19.82 & 14.58 & 12.40 & \\
\hline Pump Efficiency (\%) with varied speed & 96.44 & 97.60 & 96.94 & 94.64 & 77.99 & 70.31 & \\
\hline Brake power $(\mathrm{kw})$ & 21.15 & 29.06 & 25.65 & 20.94 & 18.69 & 17.63 & \\
\hline Electrical consume (kwh) & 326.40 & 558.19 & 425.31 & 324.84 & 305.81 & 294.65 & 2235.210 \\
\hline
\end{tabular}




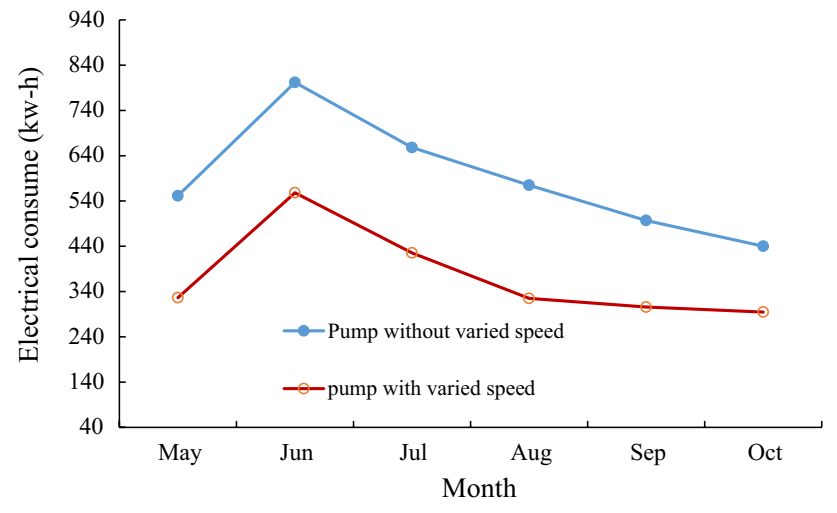

Fig. 9 Pump power consumption in different months for two modes of pump operation

under the current design conditions (constant speed pump). In the current design conditions, the pump efficiency varies between 69.6 and $74.5 \%$. The total electricity consumption is $3523.77 \mathrm{kWh}$ during the irrigation seasons.

Sprinkler irrigation system in this study is a case study from a small agricultural area; the lowest pressure in the system is not below the vapor pressure of water. Consequently, no arrangements have been made in the system for the cavitation and water hammer phenomenon. Water hammer presents negative effects to pipe lines that can be prevented by some facilities like a pressure vessel/surge tank, bypass systems, etc. Surge tanks can control both negative and positive waves that can destroy pipe lines. Detail of design and implementation of surge tanks can be found in standard fluid-mechanics books.

\section{Results and discussion}

Using Eqs. (3-5) and Fig. 6, the characteristic curves of the pump at different pump motor speeds are shown. The operating points are obtained from the intersections of these curves with the system curve. Calculations of pump speed change with required discharge changes in different months, as listed in Table 5. The table presents calculations of efficiency, brake power and electricity consumption of the sprinkler irrigation system using a pump with variable speed. The efficiency of the pump with variable speed ranges from 70.3 to $97.6 \%$. These are improvements compared to the constant speed pump. Total electricity consumption is equal to $2235.21 \mathrm{kWh}$ during irrigation seasons, which is a reduction of $1288.6 \mathrm{kWh}$ compared to the electricity consumption of the constant speed pump.

Using Eq. (4), the changes in pump speed for different months are plotted for both fixed speed and variable speed pumps. The pump speed varies from $1450 \mathrm{rpm}$ during maximum water consumption (July) to $651.88 \mathrm{rpm}$ in October. By reducing the pump impeller rotational speed, energy is conserved (Fig. 7).

Using Eq. (5), the changes in pump efficiency in different months are plotted for both fixed and variuable speeds (Fig. 8). The results show that a variable speed pump increases the average pump efficiency by $18.7 \%$. Improving the pump efficiency is greater with increase in discharge.

Figure 9 shows the changes in the power consumption of the pump in different months for the two pump modes. Power consumption in different months for the constant speed pump
Fig. 10 Energy line of the system in schematic form

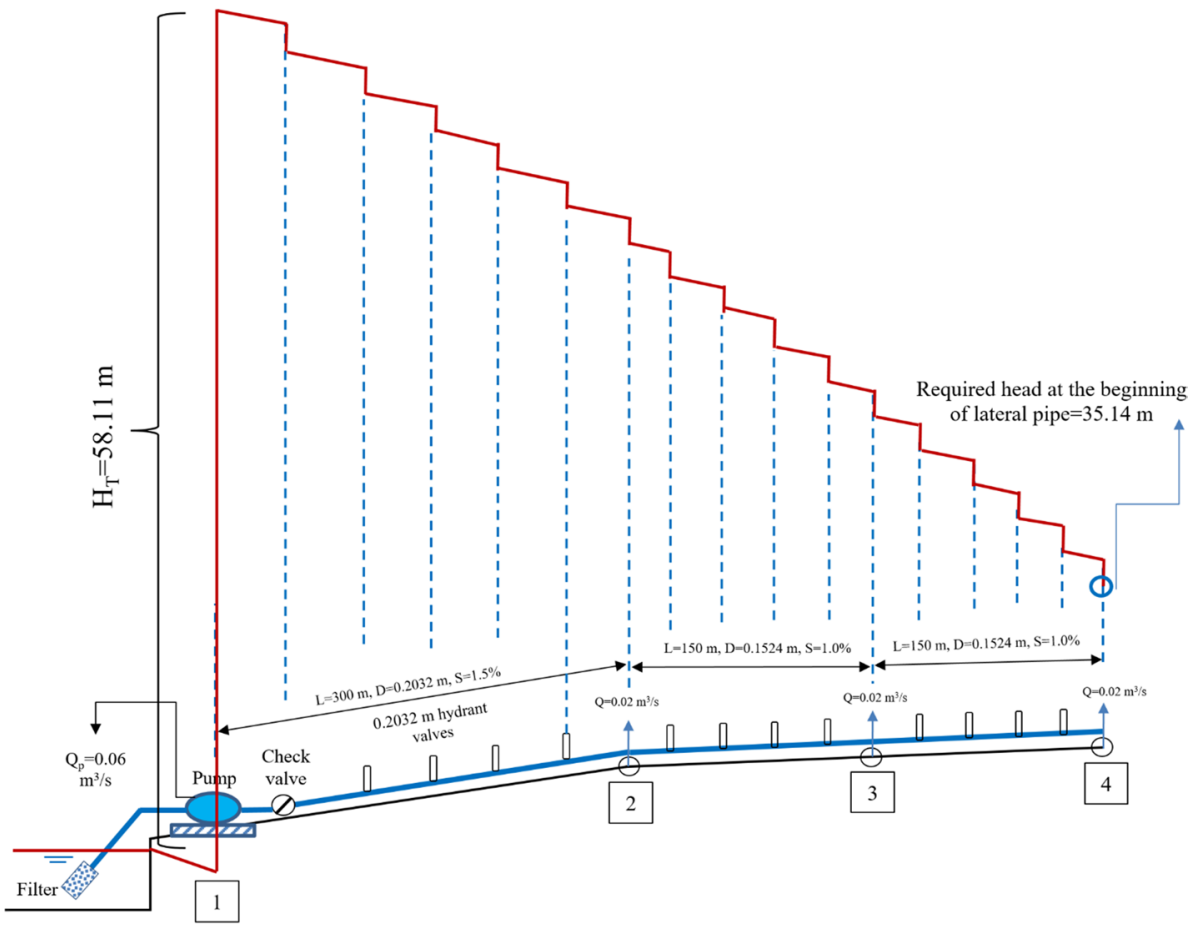


mode varies between 440.2 and $801.96 \mathrm{kWh}$. On the other hand, for the variable speed pump mode varies between 294.65 and $558.19 \mathrm{kWh}$. The results show that the variable speed pump system reduces energy consumption about $57.6 \%$ compared to the fixed speed pump. Therefore, using a variable speed pump saves electricity consumption.

In Fig. 10, the energy line of the system in schematic form is provided. Linear decreases in head are caused by frictional losses, while step change sin head corresponds to minor loss terms.

\section{Conclusions}

From this study, it is apparent that using a variable speed pump in a pressurized irrigation system increases the flexibility of the irrigation system, improves pump efficiency and reduces electrical energy consumption and cost. As the efficiency of the pump increases, the depreciation of the pump decreases and the useful life of the pump increases, thus reducing the need for maintenance.

The primary drawback of the VFD system is the initial setup investment. For a factory or a plant where multiple high horsepower motors need to be controlled using VFDs, requires high investments. In addition, VFD causes motor heating and needs special motors construction. The construction needs special types of Motor insulations, as well as the motors need to be specified for inverter rated applications.

In this study, the efficiency of stations equipped with variable speed pumps under all operating conditions exceeds that of stations equipped with fixed speed pumps. The results showed that the use of variable speed pumps not only increases efficiency but also aids in meeting water needs. The results showed that using a variable speed pump increases the average pump efficiency by $18.7 \%$.

The power consumption for a variable speed pumping station during irrigation seasons is much less than that for constant speed pump ( $\triangle P=1288.6 \mathrm{kWh})$. This is $57.65 \%$ less than with a constant speed pump. As a result, the use of variable speed pumps in pressurized systems is recommended.

Although this study refers to the pilot area for the sprinkler irrigation system, the presented methodology can be applied to other water distribution networks. The calculation of pump impeller speed, power and the operation hours of pump will be same in other projects.

Acknowledgements This research did not receive any specific Grant from funding agencies in the public, commercial or not-for-profit sectors.

Funding The author(s) received no specific funding for this work.

\section{Declarations}

Conflict of interest The authors declare that they have no conflict of interest.

Ethical approval This article does not contain any studies with human participants or animals performed by any of the authors.

Open Access This article is licensed under a Creative Commons Attribution 4.0 International License, which permits use, sharing, adaptation, distribution and reproduction in any medium or format, as long as you give appropriate credit to the original author(s) and the source, provide a link to the Creative Commons licence, and indicate if changes were made. The images or other third party material in this article are included in the article's Creative Commons licence, unless indicated otherwise in a credit line to the material. If material is not included in the article's Creative Commons licence and your intended use is not permitted by statutory regulation or exceeds the permitted use, you will need to obtain permission directly from the copyright holder. To view a copy of this licence, visit http://creativecommons.org/licenses/by/4.0/.

\section{References}

Abadia R, Rocamora C, Ruiz A, Puerto H (2008) Energy efficiency in irrigation distribution networks, I: theory. Biosys Eng 101(1):21-27. https://doi.org/10.1016/j.biosystemseng.2008.05.013

Cheng L, Zhu J, Abraham JP, Trenberth KE, Fasullo JT, Zhang B, Yu F, Wan L, Chen Z, Song X (2019) 2018 Continues record warming. Adv Atmos Sci 36:249-252. https://doi.org/10.1007/s00376-019-8276-x

Cheng L, Abraham JP, Zhu J, Trenberth KE, Fasullo J, Boyer T, Locarnini R, Zhang B, Yu F, Wan L, Chen X, Song X, Lui Y, Mann ME (2020) Record-setting ocean warmth continued in 2019. Adv Atmosph Sci 37:1-6. https://doi.org/10.1007/s00376-020-9283-7

Diaz RJA, Pérez-Urrestarazu L, Camacho-Poyato E, Montesinos P (2011) The paradox of irrigation scheme modernization: more efficient water use linked to higher energy demand. Span J Agric Res 9(4):1000 1008. https://doi.org/10.5424/sjar/20110904-492-10

Diaz RJA, Luque RL, Cobo CMT, Montesinos P, Poyato EC (2009) Exploring energy saving scenarios for on-demand pressurized Irrigation networks. Biosys Eng 104:552-561. https://doi.org/10.1016/j. biosystemseng.2009.09.001

Fernandez-Pacheco D, Ferrandez-Villena B, Molina Martinez J, RuizCanales A (2015) Performance indicators to assess the implementation of automation in water user associations: case study in southeast Spain. Agric Water Manag 151(3):87-92. https://doi.org/10.1016/j. agwat.2014.11.005

Hanson B, Weigand Z, Orloff S (1996) Performance of electric irrigation pumping plants using variable frequency drives. J Irrig Drain Eng 122(3):179-182. https://doi.org/10.1061/(ASCE)0733-9437(1996) 122:3(179)

Lamaddalene N, Khila S (2012) Energy saving with variable speed pumps in on-demand irrigation systems. Irrig Sci 30:157-166. https://doi. org/10.1007/s00271-011-0271-7

Lamaddalene N, Sagardoy JA (2000) Performance analysis of on-demand pressurized irrigation systems. FAO irrigation and drainage paper 59, Rome, $132 \mathrm{p}$

Lee T, Kim H, Lee N (2020) Performance evaluation of GaN FET-based matrix converters with $\mathrm{dv} / \mathrm{dt}$ filters for variable frequency drive applications. J Power Electron 20:844-853. https://doi.org/10.1007/ s43236-020-00070-2 
Li Y, Du J, Guo DS (2019) Numerical research on viscous oil flow characteristics inside the rotor cavity of rotary lobe pump. J Braz Soc Mech Sci Eng 41:274. https://doi.org/10.1007/s40430-019-1781-0

Li G, Cheng L, Zhu J, Trenberth KE, Mann ME, Abraham JP (2020) Increasing ocean stratification over the past half century. Nat Clim Chang 10:1116-1123. https://doi.org/10.1038/s41558-020-00918-2

Moreno MA (2008) Development of a new methodology to obtain the characteristic pump curves that minimize the total cost at pumping stations. Biosys Eng 102(1):95-105. https://doi.org/10.1016/j.biosy stemseng.2008.09.024

Khadra R, Moreno MA, Awada H, Lamaddalena N (2016) Energy and hydraulic performance-based management of large-scale pressurized irrigation systems. Water Resour Manage 30:3493-3506. https://doi. org/10.1007/s11269-016-1365-Z

Khayatzadeh F, Ghafouri J (2015) Dynamical modeling of frequency controlled variable speed parallel multistage centrifugal pumps, archive of mechanical engineering, 2300-1895. Degruyter Publ 62:347-362. https://doi.org/10.1515/meceng-2015-0020
Ramesh P, Govarthanan R, Palanisamy K, Paramasivam S (2020) Analysis of grid parameter variation with renewable energy sources on variable frequency drive DC capacitor reliability. In: Subramanian B, Chen SS, Reddy K (eds) Emerging technologies for agriculture and environment. Lecture Notes on Multidisciplinary Industrial Engineering. Springer, Singapore. doi: https://doi.org/10.1007/978-981-13-79680_20

Ruminski A (2016) Examination of variable frequency drive transformer copper cooling line failures from nuclear power plants. J Fail Anal and Preven 16:310-315. https://doi.org/10.1007/s11668-016-0090-5

Zell BP (1989) Design considerations for pumping applications of variable frequency drives. In: Pump technology. Springer, Berlin, Heidelberg. doi: https://doi.org/10.1007/978-3-662-38296-7_11

Publisher's Note Springer Nature remains neutral with regard to jurisdictional claims in published maps and institutional affiliations. 